\title{
REVIEW I Perspectives on German Popular Music
}

Michael Ahlers and Christoph Jacke Eds.

London and New York: Routledge, 2017

ISBN: 9781472479624 (HB)

\section{Giacomo Bottà \\ University of Helsinki \\ giacomo.botta@helsinki.fi}

There is a growing interest in German-speaking popular music, encompassing especially early electronic, punk, and experimental acts from both sides of the Wall, and the so-called Krautrock. These genres and their memorialization respond to the needs for cultural distinction of certain aging music collectors all over the world. However, popular music in German-speaking countries is a much more complex matter and manifests itself in a variety of past and contemporary genres, practices, and cultures, making the work of researchers a challenge.

The first attempts to make sense of popular music are German, thanks to essays on the subject by Adorno (1941) and others. Moreover, starting from the late 1980s, a whole generation of German-speaking students, pop journalists, and musicians started discussing popular music seriously, mostly outside academia, though often inside university buildings. For instance, the texts by Diederichsen (2014) and Büsser (2011) offer very innovative attempts to intellectualize and reflect about subcultures, post-punk, techno, and avant-garde, but also a clear tendency to ignore schlager, German pop, volksmusik, and Euro-trash.

Academic German popular music studies are a fascinating subject and at the same time a "fragile kaleidoscope" as Michael Ahlers and Christoph Jacke, the two editors of this volume, define them. It is only fairly recently that popular music chairs and societies have been established in German-speaking universities. The book reflects on the discipline and its history, and successfully attempts at adjusting some of the past lacks, such as the absence of attention towards the mainstream. The volume compiles thirty-four different chapters into eight thematic parts; it covers, sometimes through case studies and sometimes with general introductory texts, an impressive range of themes and subjects. 
Worth mentioning first are the two longer pieces, by Helmut Rösing and Peter Wicke respectively, in the section "Histories and Foundations". Rösing was professor for systematic musicology at the University of Hamburg (German Federal Republic) and Wicke professor for the theory and history of popular music at the Humboldt University in Berlin (until 1990, in the German Democratic Republic). They are both currently emeritiert (retired). Between them, these two scholars draft the two sides of a possible history of popular music studies in German-speaking Europe: from the West and from the East. Rösing takes a long perspective; starting with the nineteenth century and leading the reader through jazz research, schlager and critical theory, research on youth cultures, specialization, institutions and associations, and musical identities. Interesting are the references to the appearance of lexicons, a specific German academic habit apt at offering complete compiled overviews of certain subjects. Lexicons started proliferating in the 1970s and are still very much used in popular music research (see for instance www.songlexikon.de). Wicke, on the other hand, introduces the reader to the East-German academia and to the ideological premises which brought the regime to either ignore or hinder popular music. Wicke offers a very interesting account on the attitude of the political-bureaucratic apparatus, which led popular music studies to develop in a transdisciplinary way and to network internationally. Wicke contributed in 1981 to the birth of IASPM and ran the Popular Music Research Centre at the Humboldt University for several years. It is quite astonishing to read that German reunification nearly meant the end of the research centre, and that it was saved from the purge only thanks to the (WestGerman) Federation of the Phonographic Industry. Wicke goes on to define current trends in German popular music studies, like the contact with history and pedagogy and later the re-conceptualization of sound.

These two longer pieces set the scene for the development of the whole discipline and offer fascinating insights into long and complex individual careers. Seven other parts, each consisting of three to five short chapters, follow this introduction: Arts and Experiments, Mainstream and Masses, Niches and Subcultures, Politics and Gender, Germanness and Otherness, Electronic Sounds and Cities, and Media and Industries. The selection of parts is fascinating, and follows coherently the "perspectives" from the title. On offer are snippets of very different thematic and methodological approaches to the discipline, ranging from musicological analysis (Von Appen, Doehring) to integrated music media analysis (Jost); from feminist stances (Eismann) to historical research (Nathaus). Austria (Reitsamer) has an individual entry and so too a case on "Germanness" (Schiller), but other German-speaking areas of Europe, such as Switzerland, Luxembourg, and the Italian Süd Tirol, are barely mentioned. However, individual Süd Tiroler producer Giorgio Moroder has a dedicated entry, in a comparison to the German producer Frank Farian (Krettenauer). Other artists handled individually are Rammstein (Binas-Preisendörfer and Wachtmann), Scorpions (Von Appen), Modern Talking (Doehring), Kraftwerk (Matejovski), and Nina Hagen (Baßler). Whole genres and subcultures, considered in their national enactment, are punk (Meinert and Seeliger), goth (Richard), rap (Güler Saied), country (Jäger and Kirschlager), EDM (Thom), and heavy metal (Elflein). Probably for the first time in English, we find also specific studies of German phenomena of various origin and significance, such as the Beat Club on Radio Bremen (Siegfried), schlager (Mendivil), kosmische musik (Papenburg), pophörspiel (Schulze) the Hamburger Schule (Huber), "heulsusen-pop" (Volkmann), geräuschmusik (Kniola), neue Deutsche welle (Hornberger), and right-wing music (Brunner). City sounds of 
Cologne (Nieswandt) and Berlin (Meteo and Passaro) are also considered. Media and industry related chapters refer to talent shows (Ruth and Schramm) and studios (Ismaiel-Wendt).

The format of each contribution is between the one of an encyclopaedia entry and those of a book chapter, working therefore autonomously from each other but also in many ways combining knowledge, histories, and visions. The majority of the authors are scholars in various academic positions, but some of them work across the music industry, journalism, and the university, revealing the complex career trajectories in the field, and specifically in German-speaking countries.

This edited collection offers interesting kaleidoscopic reflections on German popular music cultures, through musicological, sociological, and media studies perspectives. Diederichsen, in his chapter, questions the whole idea of singing in German and argues that "all lyrics in a native language imply a missed opportunity to express oneself in a foreign language in pop music, a missed opportunity to remember that (...) one always uses a language made of symbols, which, in turn, were already complete before one started using them" (191). This volume definitely does not miss the opportunity and it successfully discusses German popular music, in English. It is a welcomed introduction to a large linguistic and cultural musicscape, for too long neglected and which international scholars should start embracing.

\section{References}

Adorno, T. W. 1941. On popular music (with George Simpson). Zeitschrift für Sozialforschung 9(1): 17-48. http://dx.doi.org/10.5840/zfs1941913

Büsser, M. 2011 Music is My Boyfriend. Texte 1990-2010. Mainz: Ventil. Diederichsen, D. 2014 Über Pop-Musik. Cologne: Kiepenheuer \& Witsch. 